\title{
Energy Dispersive X-Ray Microanalysis in conjunction with Scanning Electron Micrography to establish nematodes as bioindicators in marine fish environment
}

\author{
Anita Yadav \\ Allahabad University: University of Allahabad \\ Neerja Kapoor \\ Allahabad University: University of Allahabad \\ Amin Arif \\ Aligarh Muslim University
}

SANDEEP K MALHOTRA ( $\sim$ sandyversity@gmail.com )

Allahabad University: University of Allahabad https://orcid.org/0000-0003-2210-8234

\section{Research Article}

Keywords: Rostellascaris spinicaudatum (Malhotra and Anas, 2001), bioindicators, metal, iron, sulphur, bioremediation, raphidascaridoid, environmental impact assessment, Central West coast of India

Posted Date: January 11th, 2022

DOI: https://doi.org/10.21203/rs.3.rs-1184769/v1

License: (9) This work is licensed under a Creative Commons Attribution 4.0 International License. Read Full License

Version of Record: A version of this preprint was published at Journal of Parasitic Diseases on April 12th, 2022. See the published version at https://doi.org/10.1007/s12639-022-01480-8. 

Micrography to establish nematodes as bioindicators in marine fish environment

\author{
Anita Yadav ${ }^{1}$, Neerja Kapoor ${ }^{1}$, Amin Arif ${ }^{2}$ and Sandeep K. Malhotra ${ }^{3 \#}$ \\ ${ }^{1}$ Department of Zoology, CMP P.G. College (A Constituent College of the University of \\ Allahabad) Prayagraj-211 002, U.P., India \\ ${ }^{2}$ Department of Biochemistry, Aligarh Muslim University, Aligarh-202002, U.P., India \\ ${ }^{3}$ Department of Zoology, University of Allahabad, Prayagraj - 211 002, U.P., India \\ ${ }^{3 \#}$ Curr. Address: 16, Church Lane, Prayagraj - 211 002, U.P., India \\ \#Corresponding Author: email: philonym@gmail.com
}

Abstract: $\quad$ Energy Dispersive X-Ray Microanalysis (EDXMA) has been used as the non-invasive technique on Indian helminthes to explore the role of nematode parasites as bioindicators in the marine ecosystem of Central West coast of India for the first time. The investigation incorporates assertions on the possible benefit of such technology to elucidate bioremediating prospects that could be helpful to establish helminth parasites as a tool representing Bioindicators. The accumulation of Sulphur and Iron were analysed from a raphidascaridoid roundworm, Rostellascaris spinicaudatum (Malhotra and Anas) parasitizing marine catfish, Arius maculatus from the Central west coast of India at Goa. Quantitatively, the cuticle on oral armature comprised as much as ten times more Sulphur than iron content in the roundworm under study. However, only Carbon and Oxygen were detected over caudal papillae, where no metals or other elements were recorded.

Key words: Rostellascaris spinicaudatum (Malhotra and Anas, 2001), bioindicators, metal, iron, sulphur, bioremediation, raphidascaridoid, environmental impact assessment, Central West coast of India. 
INTRODUCTION:

Helminth parasites as Accumulator Effectors have been gaining ground in the role of Bioindicators in India. Bioremediation using live organisms is a challenging task. However, utilizing naturally available tools as predictors is even a greater sensitive challenge. Several earlier reports have illustrated that the findings of toxicological investigations could be falsified if parasitic organisms are ignored (Turc ekova et al., 2002). The accumulation bio-indication studies were involved in such studies conducted on cestodes and acanthocephalans. Some of the commonly occurring pollutants that have been acting in a natural environment directly or synergistically are inorganic metals viz. $\mathrm{Fe}, \mathrm{Zn}, \mathrm{Pb}, \mathrm{Cd}, \mathrm{Cu}$ and $\mathrm{Mn}$ (Baby et al., 2010). Since past three decades considerable interest has been generated in parasitic bioindicators to monitor aquatic biota to thrash out intricacies in the host-parasite interactions. The contribution to the discovery of parasites as water quality indicators was rightly acknowledged, but until recently the potential of bio-adaptability of endoparasites to accumulate biologically available metals in their bodies, when parasitized in fish and other aquatic biotas, was little understood. Certain contributions (Galli et al. 1998) appreciated the utility of parasites to assert the possibility of their role as a specialist bio-indicator that were competent to evade detection by the ordinarily available methods of hydrological monitoring. The role of cysteine as both catalyst and precursor in prebiotic peptide synthesis has been illustrated by Islam et al. (2020). The noticeable binding affinity of cysteine with iron to generate complexes with the potential to regulate protein function was elaborated. The amino acid, Cysteine interacted with environmentally abundant iron. These conclusions were also supported by the assertion by Baby et al., (2010).

\section{METHODOLOGY:}

The roundworms were extracted from the marine catfish, Arius maculatus at the Central West coast of India at Goa were washed with Hank's medium and then fixed in 4\% (w/v) Gluteraldehyde buffered with $0.1 \mathrm{M}$ sodium cacodylate $(\mathrm{pH} 7.4)$ containing $3 \%(\mathrm{w} / \mathrm{v})$ sucrose for $4.5 \mathrm{~h}$ at $4^{\circ} \mathrm{C}$. to conduct X-Ray Scanning Electron Microanalysis. The fishes were collected from the fresh landings at Jetti at Panjim, Goa. The tissues used for these investigations were head of $R$. spinicaudatum and the region of 
pre-caudal papillae. SEM photomicrographs were prepared with the specimens attached to the stubs, for

57 elaborate analysis of the anterior (head) and the posterior (pre-caudal papilla) regions of the worm. Each

58 body organ of three worms of the same stage of development were subjected for analysis, and these were

59 impinged twice to extract data on elements as well as metals. EDXMA (Energy Dispersive X-Ray

60 Microanalysis) was conducted using JSM6510LV JEOL (Japan) equipped with Oxford Instrument

61 INCAx-act energy-dispersive x-ray analyzer, in conjunction with SEM analysis at USIF (University

62 Sophisticated Instrumentations Facility), Aligarh Muslim University, Aligarh, U.P., India, and the results

63 presented as Figs. 1, 2, 3, 4 along with quantitative data on elements analysed from the tissues.

64

65 RESULTS:

66 The histograms evidently illustrated micro-quantities of $\mathrm{C}, \mathrm{O}, \mathrm{S}$ and Fe detected from Figs. 1,2

67 elaborating comparative assessment of contents of $\mathrm{C}, \mathrm{O}, \mathrm{S}$ and $\mathrm{Fe}$. Though in microquantities iron content

68 was higher than sulphur in different parts of the body, as analysed, but no metal deposition on papilla was

69 detected but for the universal presence of $\mathrm{C}$ and $\mathrm{O}$ in both the regions studied. The values of iron element

70 in trace quantities obtained from the present analysis as well as reported from other studies have been

71 summarized in Table1. The differentiating pattern of elemental distribution was notably specific with

72 regard to body organs of the worm; iron and sulphur being encountered over the cuticle of oral

73 armature(Figs. 1, 2, 3; Table 2), while no sulphur occurred over caudal papilla that was scrutinized for

74 element analysis (Figs. 4, 5, 6; Table 3). Quantitatively, the content of sulphur analysed was at least ten

75 times higher than iron content in the cuticle of the roundworm under study, that were expressed as weight

76 percent.

77

\section{DISCUSSION}

\section{Non-invasive detection of metals}

The differential element's accumulator response from the varied nematode body region's 
82 available in anterior part of body in the region of the head of the worm (Figs. 1-3). But no deposition of 83 any trace metal or other elements were recorded (Figs. 4-6) from the surface of the caudal papilla in the 84 hinder region of the body. These observations support the role of these worms as Accumulation Effector 85 as a component of the environmental impact assessment (EIA).

Heckmann et al. (2007) enumerated advantages to avoid multiplicity of elemental run for

87 detection and diagnosis of chemical elements by application of Energy Dispersive X-Ray Microanalysis

88 (EDXMA). The sulphur ion contributors, disulphide bonds in the twin amino acids, Cysteine and Cystine

89 that were the part of protein infrastructure of mammalian hair and horns as well as their probable

90 association with acanthocephalan egg shells and hooks were emphasized by Heckmann et al., (2007).

91 These amino acids also contributed to the strength of microstructure within the outer cuticle that also

92 facilitated movement of fluids across to further smoothen the physiological functioning of worm's various

93 systems. These macro and micro elements are important structural and functional factors, as they are

94 involved in the architecture of many enzymes and other complex molecules (Sures, 2004). The

95 predominant accumulation of essential metals like $\mathrm{Cu}, \mathrm{Fe}, \mathrm{Zn}$ and Se occurred with inhalation of food by

96 the adult roundworms (Bird and Bird, 1991; Szefer et al., 1998). The parallels in the morphological

97 infrastructure and biology of the nematodes could be drawn vis-a-vis the requirements of essential

98 elements enumerated above. Their larvae equip themselves well before encapsulation to feed on blood

99 and connective tissues available during migration through tissues of their fish hosts. The revelations by

100 Bird and Bird (1991) and Szefer et al. (1998) on the microstructure that assigned specific properties to the

101 cuticle of nematodes made it obvious that the infrastructure around wall of larvae was much more simpler

102 than the complex cuticularized skin of their adult counterparts. This indeed facilitated much more

103 smoother movement of required fluids across physiological systems of larvae.

104 The bioremediating effect of helminth parasites of fish in polluted water bodies has been a serious

105 subject of study in recent years (Khalaj et al., 2007). It has been claimed that the nematode

106 infracommunities were remediating (pollutant is in priority because of its persistence) by triggering

107 inherent accumulating instincts to absorb chemical elements inside soft body tissues of the fish. Indeed 
the survival of the fish in aquatic bodies laden with metal polluted loads were adequately supported. Physiologically, the developmental phase of parasitized helminthes and secondly the time period spent while passing through the tissues of internal organs of its fish host virtually equipped the worm with an enriched potential to accumulate metal. Other supplemental factors could be the metal characterized by specific chemical elements, site of worm infesting within the host as well as the habitat of fish.

The inorganic elements inherent in the complex long-chain fatty acids are not available to roundworms through their de novo synthesis, therefore, their compulsive dependence on hosts to acquire 115 these for completion of their metabolic activities is obvious. The essential inorganic elements required for 116 development and growth of roundworms have to be obtained from their host's body organs (Wang et al., 117 2020). The elements of primary significance from digested and absorbed, dietary nutrients are important precursors for the synthesis and metabolism of cells, most of which need be extracted from those hosts of nematodes parasitizing them (Wang et al., 2020; Khalaj et al., 2007).

The efficiency of the technique facilitating attainment of peak height to detect even trace amount of chemical elements in the tissues of fish after a 50-second run for each specimen has been reliable 122 (Heckmann, 1996). The emphasis given on technology oriented surveillance of metals assisted in the 123 detection of iron as well as sulphur only in the region of head and in no other part of body of the 124 roundworm in the present study. Thus the strength of cephalic armature is apparently specifically 125 identical in the same way as the hardness functioned in a manner as to give strength to the hooks and 126 proboscis in the anterior part of body of acanthocephalan (Heckmann et al., 2007). In earlier literature the outcome of the surveillance strategy adopted for organisms of the aquatic ecosystems by the application of atomic absorption spectrometer was reviewed by Sures (2003). Stedman

129 (2001) emphasized that the disulfide bonds coupled with sulphur ions that are the essential constituents of 130 the chemical bond infrastructure of the amino acids, viz. cystine and cysteine, are the common structural 131 constituents of keratin too in the horns of mammalian hosts which are placed higher in the ladder of 132 evolution contrary to the parasitized host fishes which were placed at the lowest order in the series of 133 evolution. 

detected in the region could be similar to the hardness of the mammalian tissue constituents described above, to assist the former in attachment and penetration through the tissues during worm migration, as 137 similar in function of proboscid hooks and egg shells of acanthocephalan, earlier concluded by Heckmann 138 et al., (2007). In further studies, Azmat et al., (2008) emphasized that nematode parasites like 139 Echinocephalus sp. and Ascaris sp. are sensitive indicator of heavy metals in aquatic ecosystems.

Heckmann et al. (2007) enumerated advantages to avoid multiplicity of elemental run for detection and diagnosis of chemical elements by application of Energy Dispersive X-Ray Microanalysis (EDXMA). The sulphur ion contributors, disulphide bonds in the twin amino acids, cysteine and cystine that comprised protein infrastructure of mammalian hair and horns as well as their probable association with acanthocephalan egg shells and hooks were emphasized by Heckmann et al., (2007).

The hardness, strength and rigidity provided by Carbon and Sulphur to the chitinized components around armature equipped head of a variety of Anisakid and Raphidascaridoid worms draws parallel to 147 the conclusions of similarity drawn with constituents of keratin i.e. the infrastructure components of hairs, 148 horns, hooves, beaks, shells, nails, claws of higher vertebrates by Radwan et al., (1912). It was significant that the study by Antoniou and Tselentis (1993) held the constitution of cuticle with specified elements like $\mathrm{S}, \mathrm{Ca}$ and $\mathrm{P}$ accountable for the strength in acuarid roundworms in addition to the specialized cordons. The examples of the marine nematodes, Tripyloides marinus, Ascaris suum and Xiphinema vuittenezi were also cited. The site specific distribution of Sulphur at the tips, mid and basal parts of spines was also encountered by the application of Energy Dispersive X-Ray Microanalysis (EDXMA) method by Heckmann et al. (2017).

The critical role of sulphur in several life processes including the protective role of sulphurcoupled ligands that occurred in natural environment has been on record (Colovic et al., 2018). The 157 adverse toxic effect and accumulation of metal ions is prevented on the body of higher mammals due to 158 the active intervention by naturally occurring sulphur in the biological systems. The chelating sites 159 generated by the sulphur-containing amino acids provide a protective platform for eliminating toxic 
metals. In view of this, it is significant that such amino acids represent an effective constituent of cell antioxidant system. On similar lines Nozaki et al. (1998) also illustrated the critical role played in the antioxidative defense of enteric parasites by the cysteine biosynthetic pathway.

The highly recognized macro-bioelement of the heavy metals has been iron, as emphasized by Nies (1999). In his opinion, it acted as a heavy metal filter to facilitate improved health conditions of the host. They may also have a beneficial effect on the health of their hosts by acting as heavy metal filters.

166 Resultantly iron was considered to be the biologically most important cation. Oscar et al. (2003) 167 concluded that the accumulator organisms reflect the element contamination level of their environment. 168 The enhanced affinity of nematodes parasitizing alligators to $\mathrm{Fe}, \mathrm{Pb}$ and $\mathrm{Cd}$ within the aquatic environment was concluded by Tellez and Merchant (2015) in their investigations. Conclusively, a lot variety of investigations conducted worldover on fish parasitic organisms have so far focused on cestodes 171 (Turc`ekova et al., 2002), acanthocephalan (Galli et al., 1998; Thielen et al., 2004; Heckmann et al., 172 2007) and other minor organisms (Galli et al., 1998). The deposition of metals, including iron on the body 173 of another marine nematode of Anisakidae viz., Contracaecum sp. (third stage larvae) was reported by 174 Leite et al. (2017), while members of Camallanidae namely, Procamallanus reportedly accumulated 175 inorganic metal, Fe on its body (Akinsanya and Kuton, 2016b). The reason of high concentration of iron analysed by Sures and Siddal (1999) in the experiments 177 conducted on Hysterothylacium reliquens was explained by Sures et al., (1999a). He assigned this to the 178 enhanced bioavailability of metals within the physiological system of the experimental organism, i.e. fish 179 due to the presence of bile acid inside the alimentary canal at the site of infection. Calculated 180 bioavailability of the iron amino acid chelate was $75.0 \%$ compared to $27.8 \%$ for $\mathrm{FeSO}_{4}$. As suggested by 181 Fairweather- Tait, et al. (1992), this study also demonstrated that the greater bioavailability of the iron 182 amino acid chelate allows for the rapid incorporation of iron into hemoglobin first, followed by a quicker 183 repletion of depleted iron pools (i.e. serum ferritin) than is possible with $\mathrm{FeSO}_{4}$ (Pineda and Ashmead, 184 2001). This study may well open up a new area to intricately explore the possible amending effects of 185 parasites on the biomarker responses particularly because most of the time moderate levels of iron in 
water or nutrients provide a supportive strength for the survival, growth and development of nematodes parasitic in fish (Sures et al., 2017). This conclusion emanated from the fact that the mixing of nitrates and iron in the upwelling zones of riverine stretch, the mixing of dietary feed with the available iron in the euphotic zone habitation of $A$. maculatus, could easily provide enhanced iron rich dietary constituents to this fish host through which the cuticle of nematodes, $R$. spinicaudatum availed opportunity to absorb extra iron available.

\section{CONCLUSIONS:}

An elaborate narrative has been developed by Parasitologists to assert (Sures and Siddall, 1999) that the environmental value of certain endoparasites should credibly be required a more emphatic attention. The approaches, methodology and academic prowess of ecological parasitologists and aquatic ecologists must address to common goals at large to develop skills to substantiate parasitic bioindicators. The earlier studies have faltered to ignore the significance of helminth parasites as contributors to sinks for heavy metals (Sures and Siddall, 1999) within a fish host. It is thus quite likely that a host fish could have much more potential to tolerate heavy metals in the aquatic ecosystems than that have been actually reported (Hofer and Lackner, 1995; Gunkel, 1994; Köck, 1996) till recent times notwithstanding the

202 heavier amount of contaminants that helminthes parasitizing such fish could have been known (Sures, 2001). Therefore, this is the first validated attempt in the Gangetic freshwater ecosystems to confirm the role of nematodes as sensitive bioindicators that could prove to be vital as a viable tool for environmental monitoring. In a way, like the response of organisms to abiotic factors, such organisms/animals/plants that were susceptible to a wide range of parasitic organisms or their developmental stages could be termed as

207 Euryparasitic, and when such fauna had a narrow range of susceptibility to parasitic organisms or their 208 developmental stages, these are termed as stenoparasitic. Morsy et al. (2011) elaborated sustainability 209 potential of anisakid worms, a closer taxonomic ally of rhabdiscaridoid roundworms that are the subject 210 of present study, as potential instruments to monitor environmental pollution which had the capacity to 211 help in the survival of their fish hosts by removing heavy metals from within the aquatic ecosystems. 


\section{Acknowledgements}

AY and NK are thankful to the Head, Department of Zoology, CMP P.G. College, (A Constituent

214 College of the University of Allahabad), and AA is grateful to Aligarh Muslim University for facilities.

215 The assistance from USIF, Aligarh is thankfully acknowledged.

217 Conflict of interest: The authors declare that there is no conflict of interest.

Ethical approval: No approval by an ethical committee was required to achieve the goals of the present study.

221

222

\section{REFERENCES:}

223

224

Akinsanya B, Kuton MP (2016a) Bioaccumulation of heavy metals and parasitic fauna in Synodontis 225 clarias (Linnaeus, 1758) and Chrysichthys nigrodigitatus (Lacepede, 1803) from Lekki Lagoon, Lagos, Nigeria. Asian Pac J Trop Dis 6:615-621 doi: 10.1016/S2222-1808(16)61096-4

227

228

Akinsanya B, Kuton MP (2016b) Parasitic diseases and heavy metal analysis in Parachanna obscura 229 (Gunther 1861) and Clarias gariepinus (Burchell 1901) from Epe Lagoon, Lagos, Nigeria. Asian Pac J 230 Trop Dis 6:685-690 doi: 10.1016/S2222-1808(16)61110-6

231

Antoniou M, Tselentis Y (1993) Studies on Echinococcus granulossus using the scanning electron microscope II. The hooks. Parasitol Res 79:543-546 Springer-Verlag. through Nematode Parasite of Fish. Biotechnology 7 (1): 139-143. 
Bird AF, Bird J (1991) The Structure of Nematodes. New York: Academic 2.

241

242 Colovic MB, Vasic, VM, Djuric DM, Krstic, DZ (2018) Sulphur-containing amino acids: Protective role 243 against free radicals and heavy metals. Curr Med Chem 25(3):324-335. doi: $244 \quad 10.2174 / 0929867324666170609075434$.

Dural M., Genc E., Sangun M.K., Güner Ö. 2011. Accumulation of some heavy metals in 247 Hysterothylacium aduncum (Nematoda) and its host sea bream, Sparus aurata (Sparidae) from North248 Eastern Mediterranean Sea (Iskenderun Bay). Environ Monit Assess 174(1-4): 147-155. 249 DOI:10.1007/s10661-010-1445-0

Fairweather- Tait SJ, Fox TE, Wharf SG, Ghani NA (1992) A preliminary study of the bioavailability of 252 iron- and zinc- glycine chelates. Food Add Contam 9: 97-101.

254 Foden, C.S., Islam, S., Fernandez-Garcia, C., Maugeri, L.M., Sheppard, T.D. and Powner, M.W. (2020)

255 Probiotic synthesis of cysteine peptides that catalyze peptide ligation in neutral water. PLOS One, 370 256 (6518):865-869 doi: 10.1126/science.abd5680. parasites compared to their fish host. Chemosphere 37: 2983-2988. 
Genc E, Sangun MK, Dural M, Can MF, Altunhan C (2008) Element concentrations in the swimbladder

parasite Anguillicola crassus (Nematoda) and its host the European eel, Anguilla anguilla from Asi River (Hatay-Turkey). Environ Monit Assess, 141:59-65

Gunkel G (1994) Bioindikation in aquatischen Ökosystemen. Fischer Verlag, Jena, Stuttgart.

Heckmann R A (1996) Energy dispersive x-ray microanalysis in conjunction with electron optics, a tool for analyzing aquatic animal diseases and deaths. Micro Anal 17:27-29.

Heckmann RA, Amin OM, Standing MD (2007) Chemical Analysis of Metals in Acanthocephalans Using Energy Dispersive X-Ray Analysis (EDXA) in Conjunction with a Scanning Electron Microscope (SEM). Comp Parasitol 74(2): 388-391.

Hofer R and Lackner R (1995) Fischtoxikologie - Theorie und Praxis. Fischer Verlag, Jena.

Khalaj V, Eslami H, Azizi M, Nuria R-G, Bromley M (2007) Efficient Downregulation of alb1 Gene Using an AMA1-Based Episomal Expression of RNAi Construct in Aspergillus fumigates. Microbiol Let 270(2): 250-254.

Köck G (1996) Die toxische Wirkung von Schwermetallen auf Fische. In: Steinberg C, Bernhardt H and Klapper H (eds.) Handb Angew Limnol pp 1-167. Ecomed Verlagsgesellschaft, Landsberg am Lech.

Le ITY, Zimmermann, S., Sures, B. 2016. How does the metallothionein in induction in bivalves meet the criteria for biomarkers of metal exposure. Environ. Pollut., 212, 257-268. 
Leite L.A., Pedro N.H., de Azevedo R.K., Kinoshita A., Gennari R.F., Watanabe S., Abdallah V.D. 2017. Contracaecum sp. parasitizing Acestrorhynchus lacustris as a bioindicator for metal pollution in the Batalha River, southeast Brazil. Sci. Total Environ. 575:836-840. doi: 10.1016/j.scitotenv.2016.09.132.

Malhotra Sandeep K, Anas M (2001) A unique piscine ascaridid Rostellascaris spinicaudatum gen et sp n with key to genera of subfamily Ascaridinae. In: Professor V.N. Capoor Commem Vol, GBP Univ Agric 294 Technol, Pantnagar 20-25, 1-3 Nov.

295

Morsy K, Bashtar A-R, Abdel-Ghaffar F, Mehlhorn H, Al Quraishy S, El-Mahdi M, Al-Ghamdi A, 297 Mostafa N (2012) First record of anisakid juveniles (Nematoda) in the European seabass Dicentrarchus labrax (family: Moronidae), and their role as bio-indicators of heavy metal pollution. Parasitol Res 110:

300

Nachev M, Schertzinger G, Sures B. (2013) Comparison of the metal accumulation capacity between the acanthocephalan Pomphorhynchus laevis and larval nematodes of the genus Eustrongylides sp. infecting barbel (Barbus barbus). Parasit Vect 6, 21. https://doi.org/10.1186/1756-3305-6-21.

304

Nies DH (1999) Microbial heavy metal resistance. Appl Microbiol Biotechnol 51: 730-750. cloning and characterization of the genes encoding two isoforms of cysteine synthase in the enteric protozoan parasite Entamoeba histolytica. Mol Biochem Parasitol 97 (1-2): 33-44.

Oscar R, Roberto C, Maria BG, Marta D, Paolo L (2003) Trace element concentrations in freshwater 312 mussels and macrophytes as related to those in their environment. J Limnol 62(1): 61-67. 313 doi:10.4081/jlimnol.2003.61 
314 Pineda D, Ashamead H DeWa (2001) The absorption and metabolism 01 iron amino acid chelate.

315 Archivos Latinoamericanos de Nutricion ver. Imp. ISSN0004-0622. ALANv.51.1supl.1

316 Caracasmar.:19pp.

317

Radwan NA, Abou Shafeey HE, Khalil AI (2012) Chemical characterization of tegumental spines of four 0975-3702 \& E-ISSN: 0975- 9182, 4(2), 100-105.

Stedman J K (2001) Stedmans Medical Dictionary for the Health Professions. 4th ed. Lippincott, 323 Williams and Wilkins. Philadelphia. 1597 pp.

Sures, B (2003) Accumulation of heavy metals by intestinal helminths in fish: an overview and perspective. Parasitol. 126 (Suppl.): S53-S60. pollution. Tr Parasitol 20, 170-177. fish host, chub (Leuciscus cephalus). Exp Parasitol 93: 66-72. Parasitol Today 15: 16-21. and where we go in Environmental Parasitology. Parasit Vect, 10: 57pp. 
Szefer P, Rokicki J, Frelek K, Skora K, Malinga M. (1998) Bioaccumulation of selected trace elements in

341 lung nematodes, Pseudalius inflexus, of harbor porpoise (Phocoena phocoena) in a Polish zone of Baltic

342 Sea. Sci Tot Environ 220: 19-24 doi:10.1016/S0048-9697(98)00221-6.

Tellez M, Merchant M (2015) Biomonitoring heavy metal pollution using an aquatic apex predator, the American alligator, and its parasites. PLoS ONE 10:e0142522. doi: 10.1371/journal.pone. 0142522.

Thielen F, Zimmermann S, Baska F, Taraschewski H, Sures B (2004) The intestinal parasite, Budapest, Hungary. Environ Poll 129, 421-429.

Turčekova’ L, Hanzelova` V, S` pakulova’ M (2002) Concentration of heavy metals in perch and its endoparasites in the polluted water reservoir in Eastern Slovakia. Helminthologia 39(1):23-28

Wang, X., Zhang, L., Zhang, L., Wang, W., Wei, S., Wang, J., Che, H. and Zhang, Y. (2020) Effects of excess sugars and lipids on the growth and development of Caenorhabditis elegans. Gene and Nutrition. 15, 1. https://doi.org/10.1186/s12263-020-0659-1

357 Fig.1. SEM of head of Rostellascaris spinicaudatum (Ventral view)(Purple square represents measured 358 area). Typical chart recording elemental composition using energy -dispersive X-ray Microanalysis 359 (EDXMA) in conjunction with a Scanning Electron Microscope.

360 Fig.2. Head of Rostellascaris spinicaudatum for observed chemical elements after a 50-Sec run include 361 specific peaks of different elements.

362 Fig.3. Bar diagrams to show quantitative illustration of peaks as depicted in Fig. 2.

363 Fig.4. SEM of pre-cloacal papillae (Dorsal view)(Purple square represents measured area). Typical chart 364 recording elemental composition using energy -dispersive X-ray Microanalysis (EDXMA) in conjunction 365 with a Scanning Electron Microscope. 
366 Fig.5. Pre-cloacal papilla (Dorsal view) of Rostellascaris spinicaudatum for observed chemical elements 367 after a 50-Sec run include specific peaks of different elements.

368 Fig.6. Bar diagrams to show quantitative illustration of peaks as depicted in Fig. 5. 


\section{Figures}

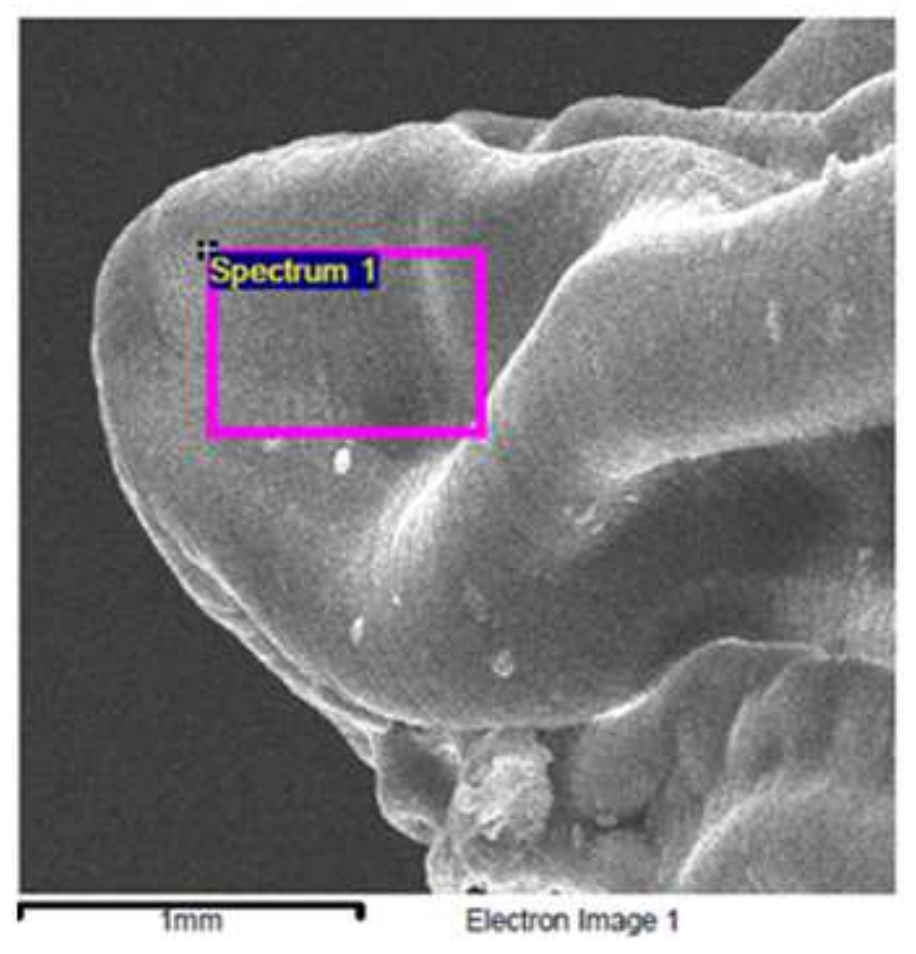

\section{Figure 1}

SEM of head of Rostellascaris spinicaudatum (Ventral view)(Purple square represents measured area). Typical chart recording elemental composition using energy - dispersive X-ray Microanalysis (EDXMA) in conjunction with a Scanning Electron Microscope. 


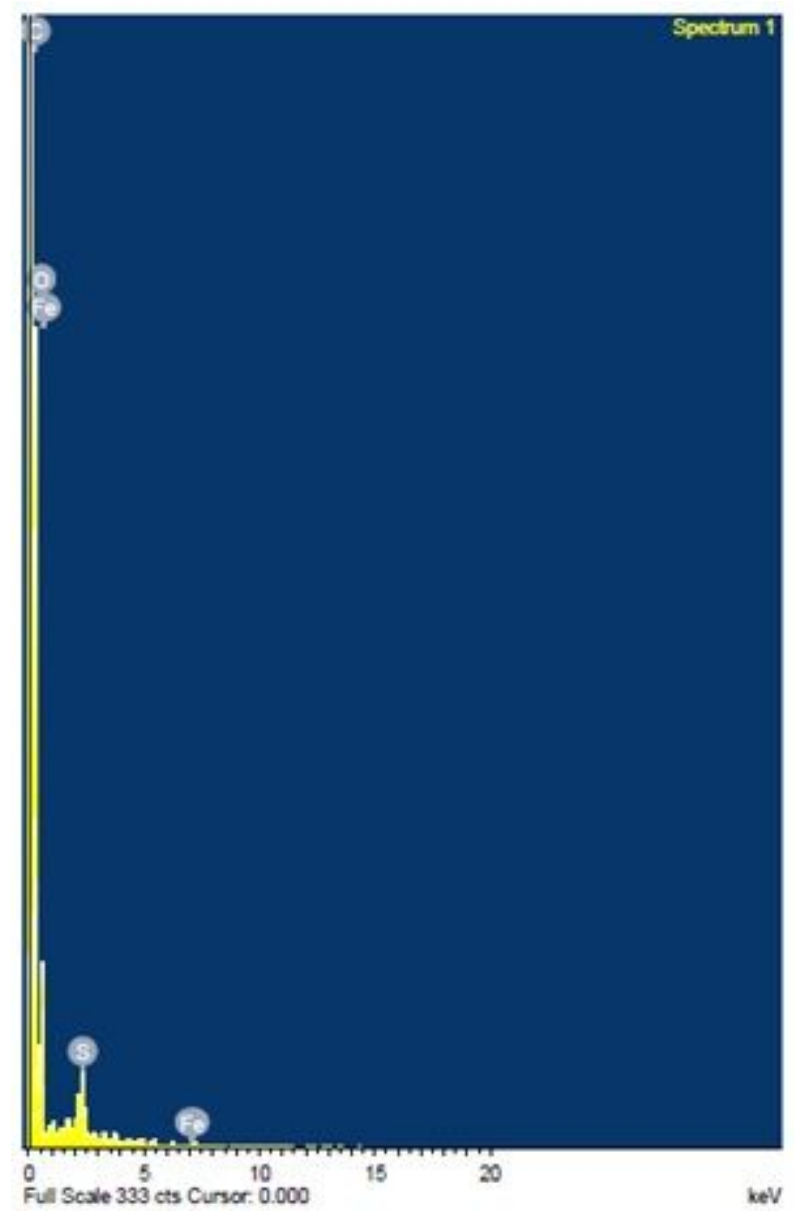

Figure 2

Head of Rostellascaris spinicaudatum for observed chemical elements after a 50-Sec run include specific peaks of different elements. 


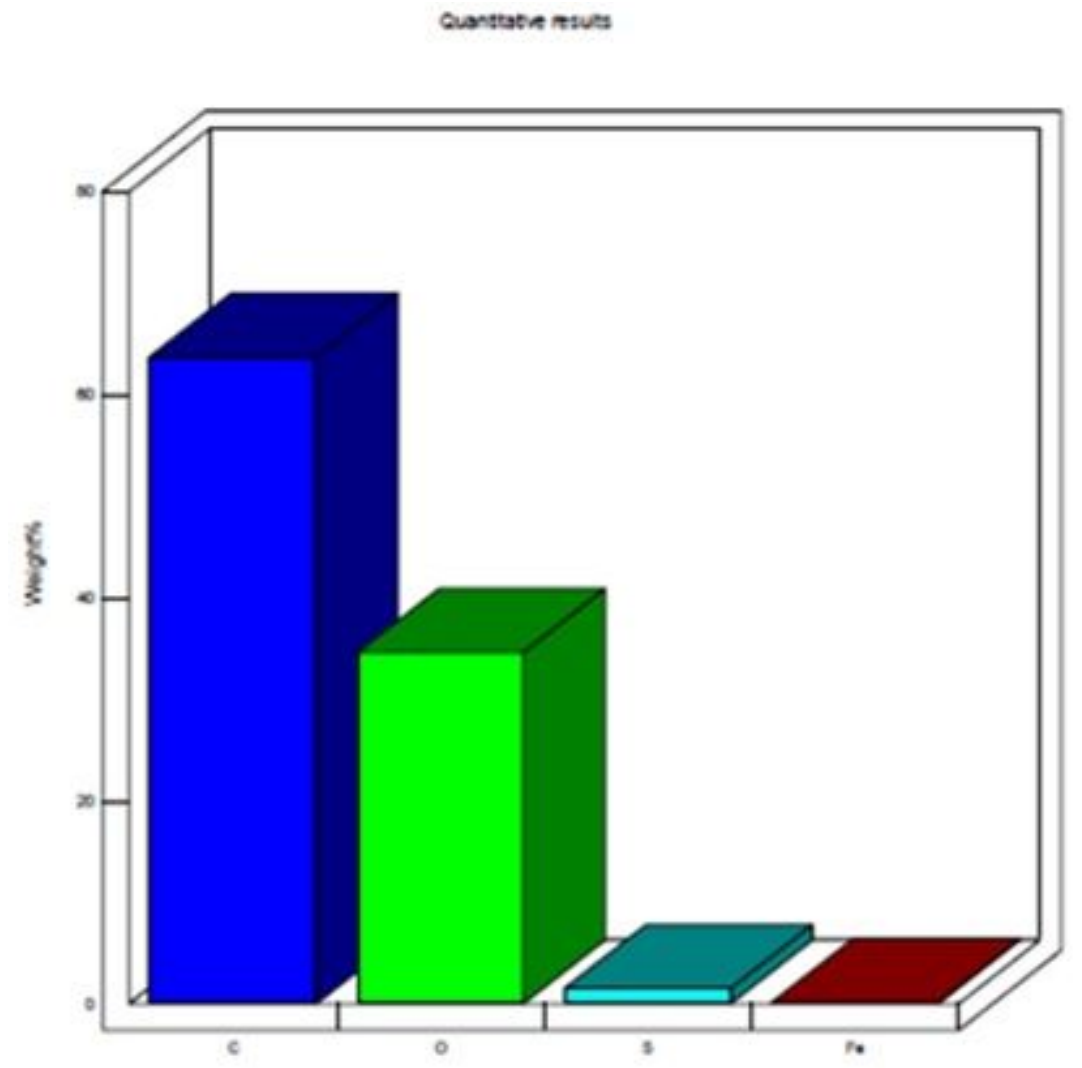

Figure 3

Bar diagrams to show quantitative illustration of peaks as depicted in Fig. 2.

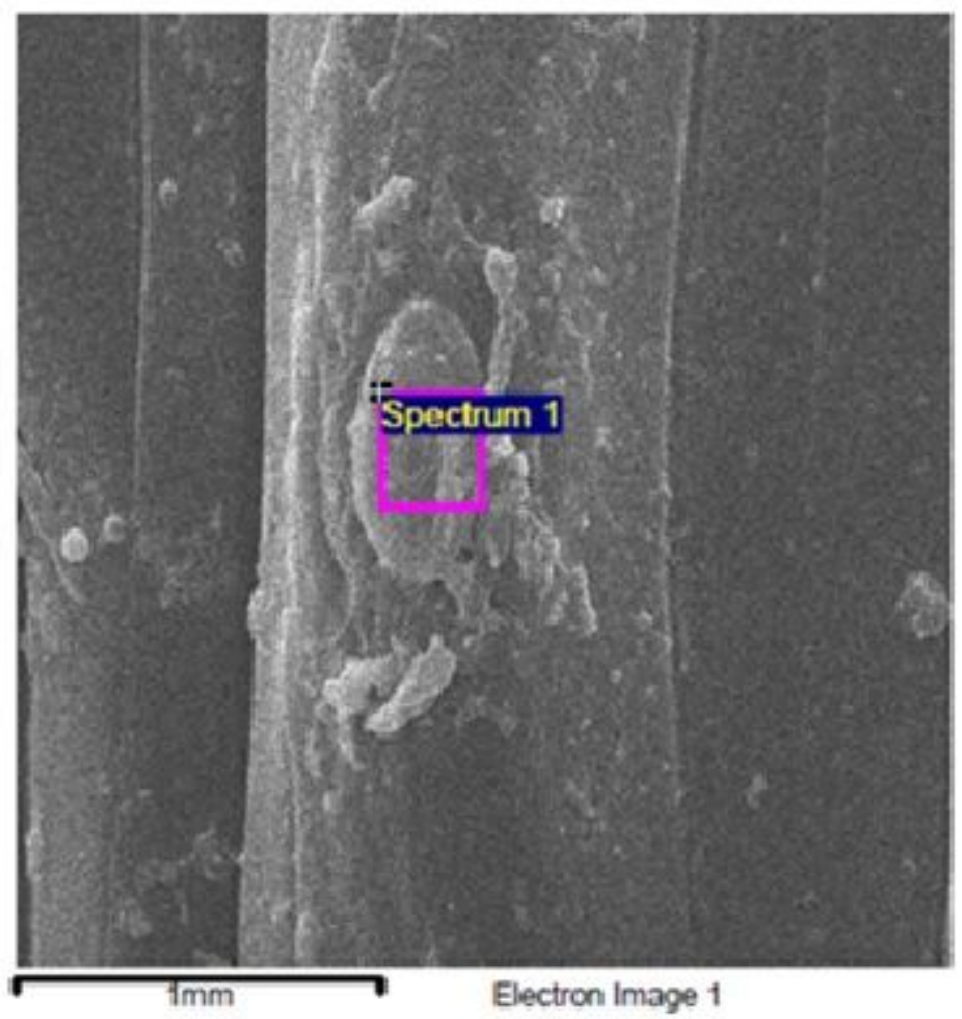

Figure 4 
SEM of pre-cloacal papillae (Dorsal view)(Purple square represents measured area). Typical chart recording elemental composition using energy -dispersive X-ray Microanalysis (EDXMA) in conjunction with a Scanning Electron Microscope.

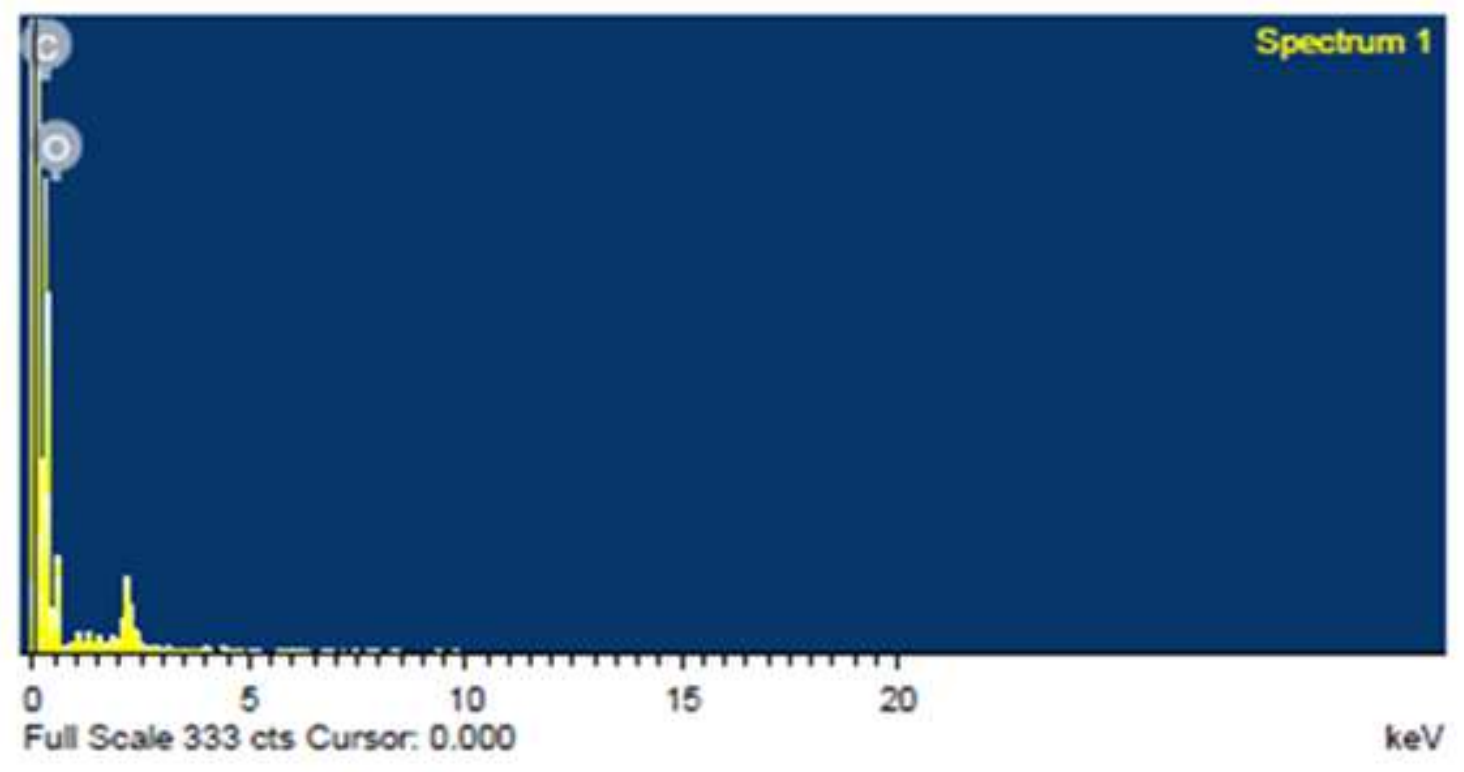

\section{Figure 5}

Pre-cloacal papilla (Dorsal view) of Rostellascaris spinicaudatum for observed chemical elements after a 50-Sec run include specific peaks of different elements. 


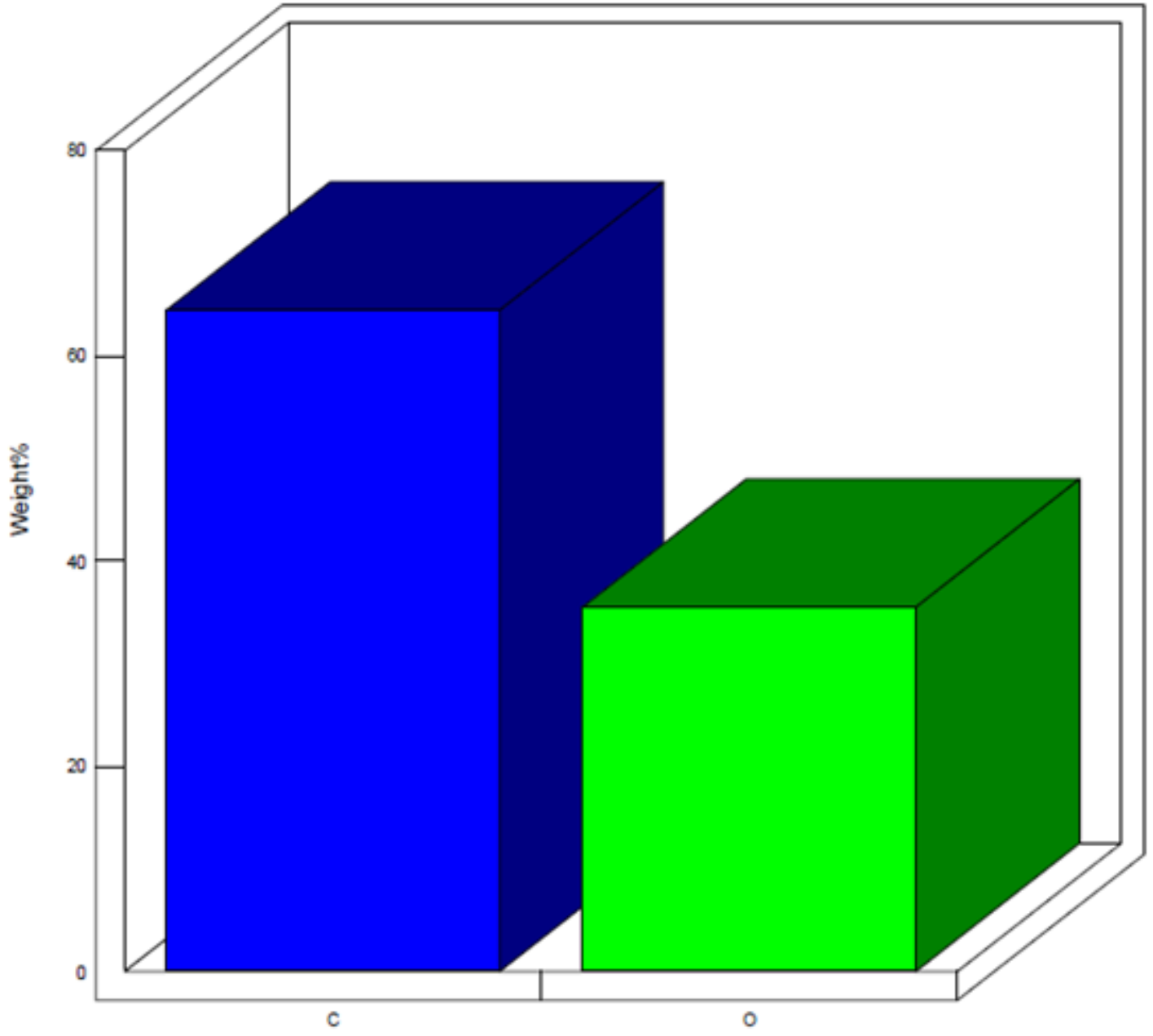

Figure 6

Bar diagrams to show quantitative illustration of peaks as depicted in Fig. 5.

\section{Supplementary Files}

This is a list of supplementary files associated with this preprint. Click to download.

- BioindiTable1.docx

- BioindiTable23.docx 